\title{
APPLICABILITY OF AN UNMANNED AERIAL VEHICLE SURVEYING TO THE MEASUREMENT OF DIGITAL TERRAIN MODEL
}

\author{
*Heikkilä, R. \\ University of Oulu \\ Erkki Koiso-Kanttilankatu 1 \\ Oulu, Finland \\ (*Corresponding author: rauno.heikkila@oulu.fi) \\ Heikkilä, J. \\ Pieneering $O y$ \\ Hylkeenpyytäjänkatu 1 \\ Helsinki, Finland \\ Mikkonen, M. \\ Mitta Oy \\ Laakeritie 9 \\ Oulu, Finland
}

\begin{abstract}
As a part of a large research and development program in Finland, a system calibration for an UAV measurement method having practical experiments in a Jorvas Railway Yard design and construction project. The Railway yard construction are was measured using an UAV measurement device by Smartplanes (Smartone) and using some reference points measured by a GNSS device. The measured data was cleaned, combined and adjusted through Least Squares Optimization using the software developed by a Finnish company Pieneering Oy. As references, two different laser scans as well as total station surveys were used. For applicability evaluation, the accuracy of measurement, the reliability of measurement, and the economy of measurement were used. Based on the comparisons, the achieved precision of the UAV measurement was high, instead the accuracy of measurement was not sufficient in this case. The principle of this photogrammetric measurement includes a lot of redundant observations making it possible to achieve a high level of reliability. The economy in this Railway Yard Design project was not able to achieve.
\end{abstract}

\section{KEYWORDS}

Unmanned aerial surveying, digital terrain model.

\section{INTRODUCTION}

All required surveys should be performed with sufficient accuracy, adequate reliability, and acceptable economics relative to the application area (Heikkilä 1996, Cooper 1987, Heikkilä et al 2010). Generally:

(1) Accuracy of measurement means the capability to produce errorless results.

(2) Reliability of measurement is the capability to maintain accuracy during measurements.

(3) Economy of measurement means the proportion of the economic advantages produced by the measurement relative to the measurement costs.

The accuracy requirement presupposes the systematic errors of measurements to be well-corrected or controlled so that the adequate accuracy of the final results can be obtained. The magnitude of random errors has to be sufficiently decreased to achieve sufficient measurement certainty. The reliability requirement presupposes the different gross, systematic, and random errors occurring in practical measurements to be detected and controlled among the observations. One should be able to eliminate gross 
errors as well as correct systematic errors. One should always be able to estimate random errors in order to enable the evaluation of uncertainty and thus the usefulness of the results. The economic profitability of measurements sets that the costs of the measurements should be lower than the financial advantages obtained (Heikkilä 1996, Cooper 1987, Sydenham 1982 \& 1983).

Three-dimensional initial data from site are needed for the design and construction phases of railways. The creation of 3-D initial data model is also the first and necessary step to BIM based modeling and total process. In this research, the measurement object was an existing railway yard area located in Jorvas, Kirkkonummi, Southern Finland. The aim of the measurement was to capture data of digital terrain model (DTM), current rails and other built structures from the measurement range area. The applicapility evaluation was made to an unmanned aerial surveying technique (UAV) having photogrammetric principle of measurement. The UAV device is an autonomous small-size airplane or UAS robot. This type of UAV measurement devices have been more and more marketed to the purposes of DTM measurements. The main parts of the systems include a small-size airplane, remote control system, pc software for the planning of measurement operation and flying control as well as a special software for data analyse and modelling purposes. In this project, the modeling software and services provided by Pieneering Oy, Finland, were used.

The UAV has a photogrammetric principle of measurement, where one of the most interesting derivative quantities are orthophotos. Generally, an orthophoto, orthophotograph or orthoimage means an aerial photograph geometrically corrected ("orthorectified") such that the scale is uniform: the photo has the same lack of distortion as a map. Unlike an uncorrected aerial photograph, an orthophotograph can be used to measure different true distances or coordinates needed, because it is an accurate representation of the Earth's surface, having been adjusted for topographic relief, lens distortion, and camera tilt. (Wikipedia).

The aim of this research was set to evaluate the applicability of the UAV measurement pricle to the measurement of the initial data model for railway yard design and construction purposes. Further, the aim was to utilize this information also in the development of the InfraFINBIM specifications for BIM based initial data modelling.

\section{METHODS}

The UAV measurement was executed using Smart One UAV measurement device. The survey was operated by company Kuvaparonit Oy, the measurement time was about 20 minutes. The reference measurements were made using Leica Scanstation C10 laser scanning system with Leica Viva TS15 total station, Riegl VZ-1000 laser scanning system together with Trimble S6 total station.

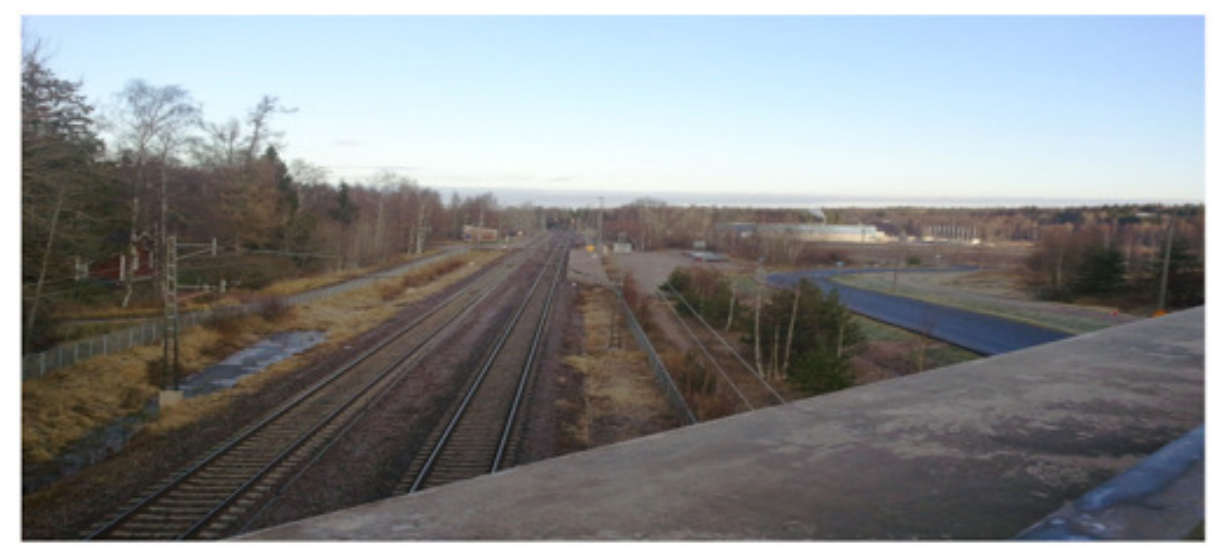

Figure 1. A scene to the pilot project - Jorvas Railway Yard area, Southern Finland. 
The measurements, analyses and comparisons between UAV measurement results and the reference measurement results were made using EUREF-FIN and N2000 coordinate system. The reference points around the measurement range were made using RTK-GNSS system, thus the evaluated accuracy of measurement was about $\pm 3 \mathrm{~cm}$ (height direction). From the UAV observations total 23806 points were calculated to the point cloud. From the total range a special comparison area of $23000 \mathrm{~m} 2$ was selected. For the comparisons, $1 \times 1 \mathrm{~m} 2$ network was used meaning that the height of every surface models $(z)$ were observed accurately from the same $x y$ position. The reference point clouds of the Riegl and Leica scans were seen to have similar accuracy and the surfaces were combined together.

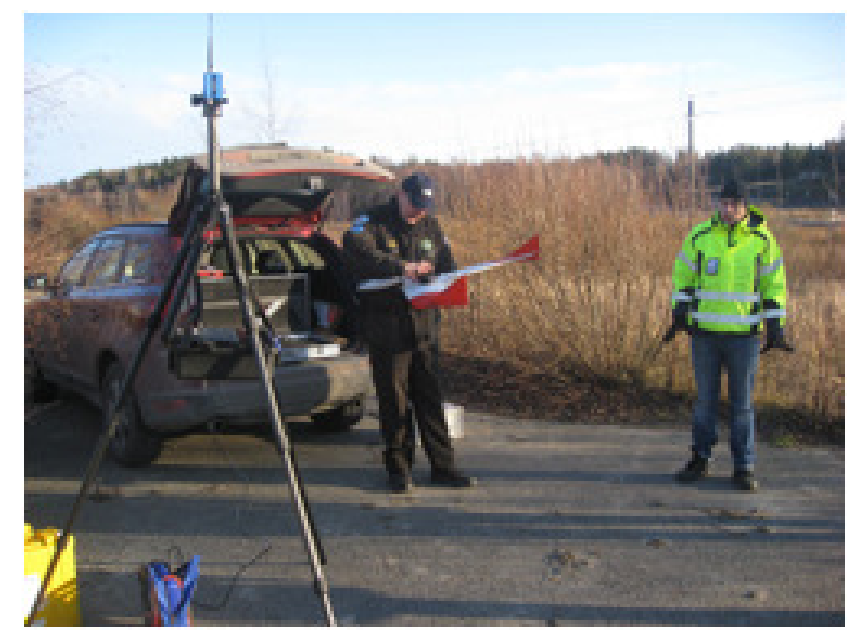

Figure 2. The surveying experiment using Smart One UAV device used by Kuvaparonit Oy, Finland.

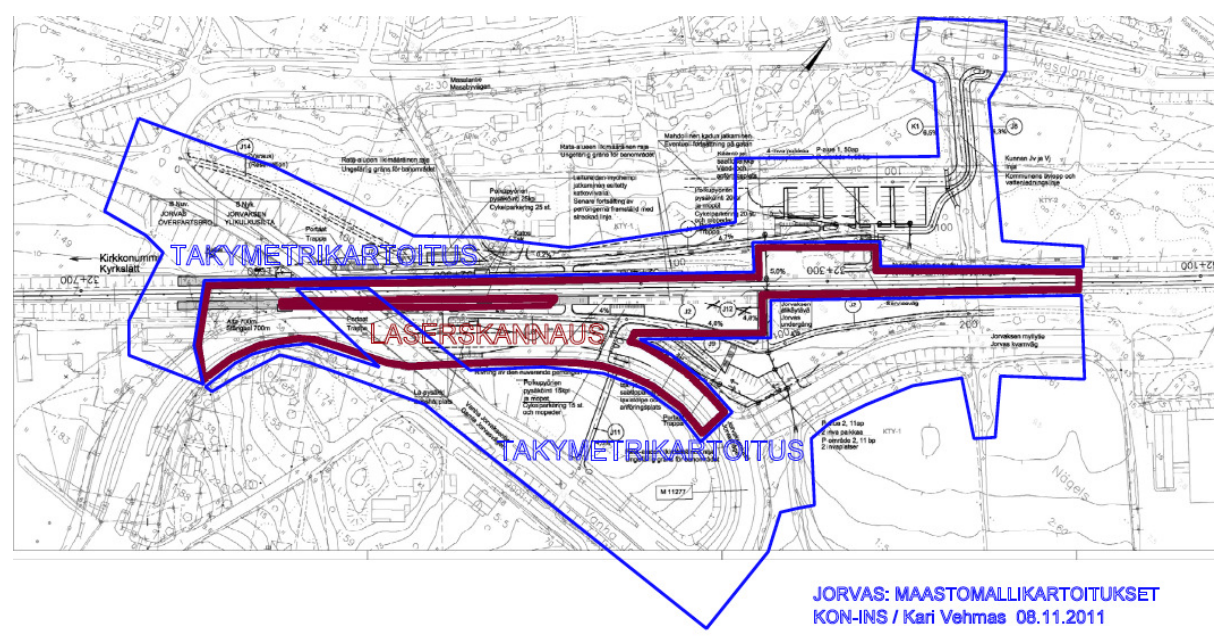

Figure 3. Map of the experimental areas for the UAV measurements and the reference measurements, i.e. 3-D laser scans and total station surveys.

\section{RESULTS}

The quality of the orthophotos produced by the UAV method was evaluated to be very good. The quality of UAV point cloud was good or inside some areas not good. When considering the accuracy of measurement, the surface measured by the UAV method was about $-1.7 \mathrm{~cm}$ below the reference surfaces, which were measured by the two laser scanning system. The standard deviation was $22 \mathrm{~cm}$. There were 
observed a few higher deviations between the surfaces (evaluated to be gross errors). The movements of the shadows of trees during the UAV measurement have caused significant errors on the UAV measurements. The area of an asphalt pavement area was not able to measured with high accuracy - there were not able to observe any clear details and points for the photogrammetric adjustment calculations.

The applicability of these ground laser scanning systems was seen to be questionable in this case. While the scanning device is set just on the ground base, the measurement geometry will be very limited to capture points from the ground surface. Also any trees, structures or other obstacles limit easily the sight to the measurement object or ground surface. Both the used laser scanning systems, Leica and Riegl, were evaluated to have quite the same accuracy of measurement. As an example, the deviation between these scans on the deck of the bridge in the range area, was calculated to be $\pm 1 \mathrm{~mm}$, and on the clear ground area about $\pm 1 \mathrm{~cm}$. The total stations were made from the area, where the ground surface was covered by trees and bushes, which prevented the observation of ground surface using UAV device. Thus these measurements were not able to utilized for comparisons.

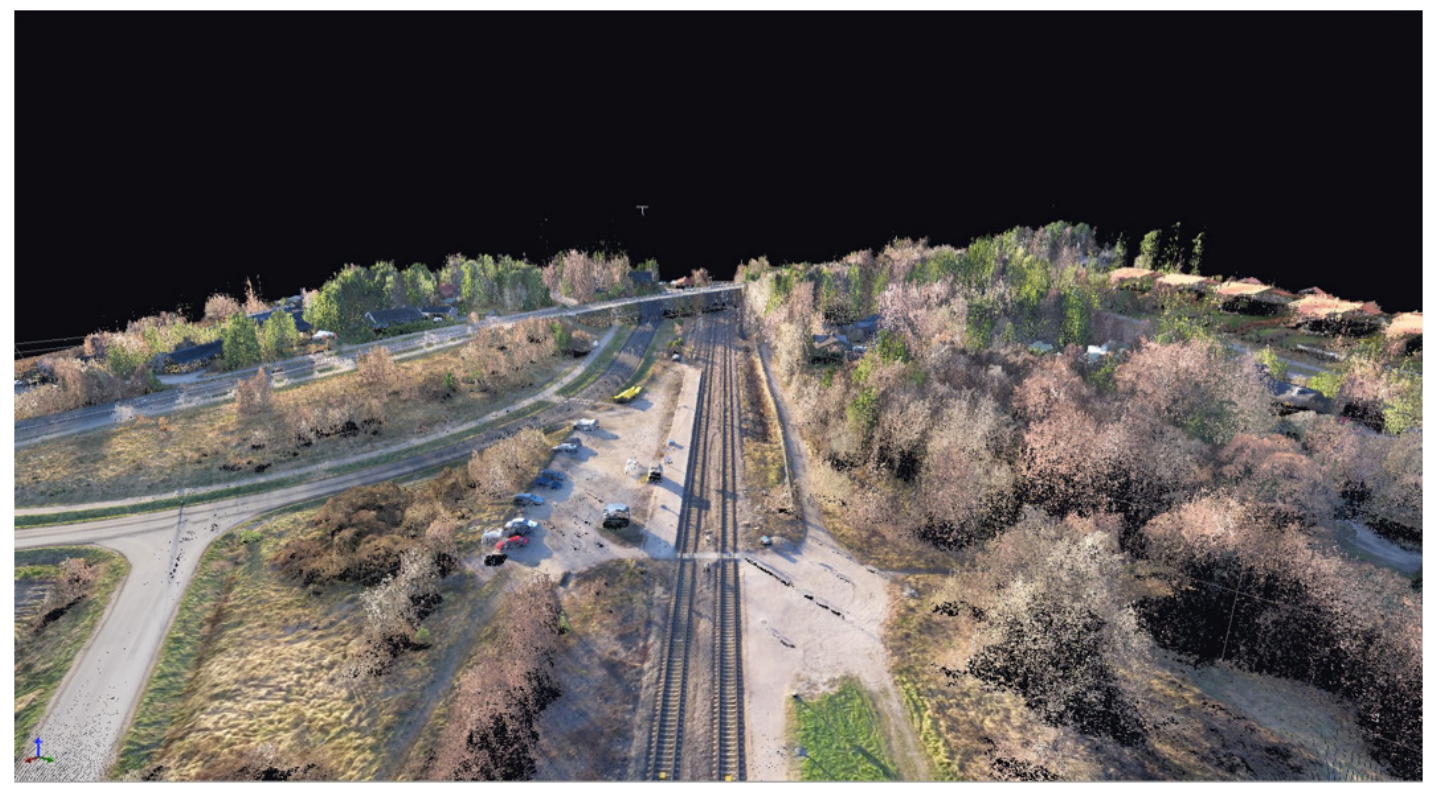

Figure 5. The UAV measurement result - coloured point cloud. 


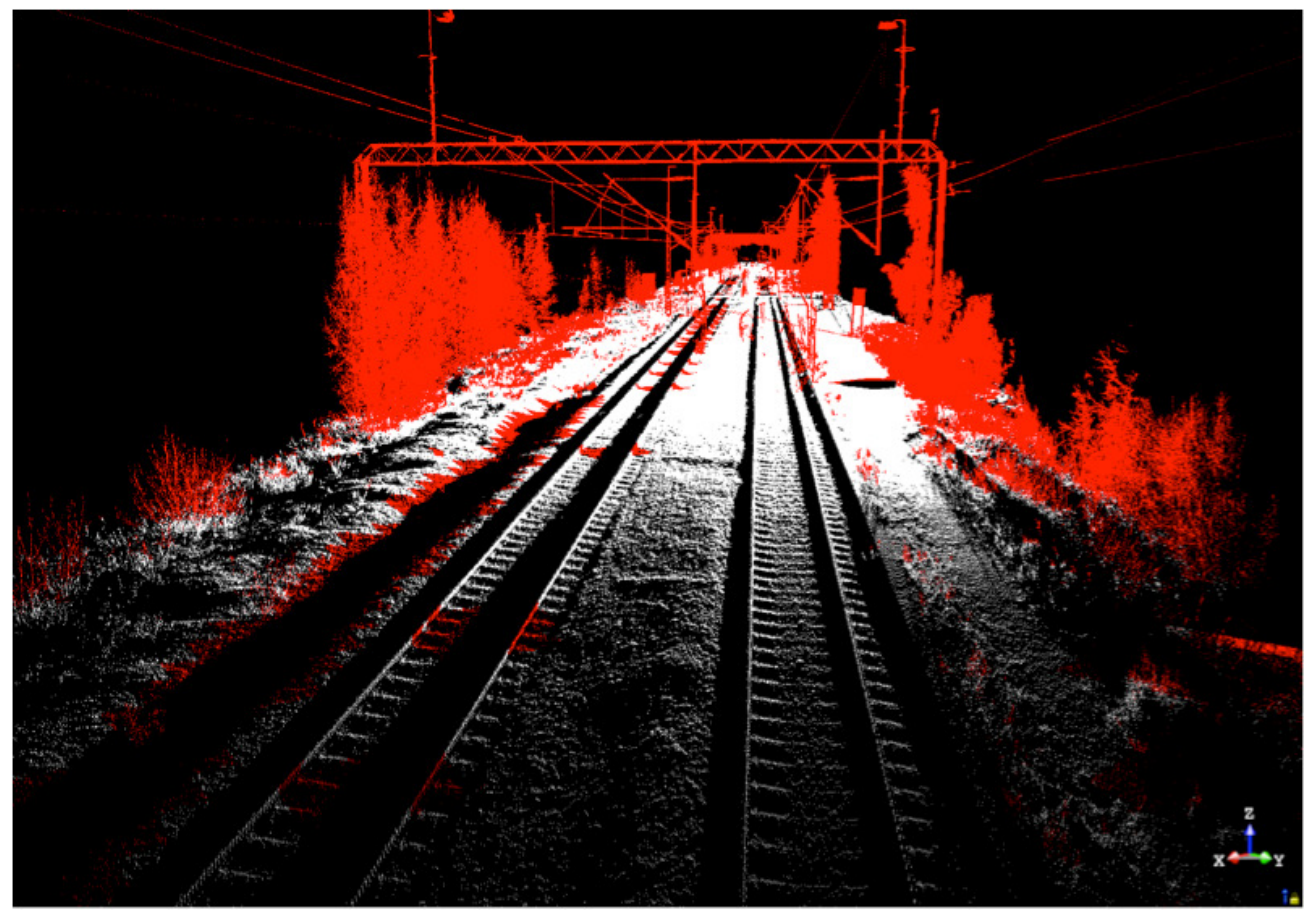

Figure 6. The reference point cloud measured by Leica C10 laser scanning system.

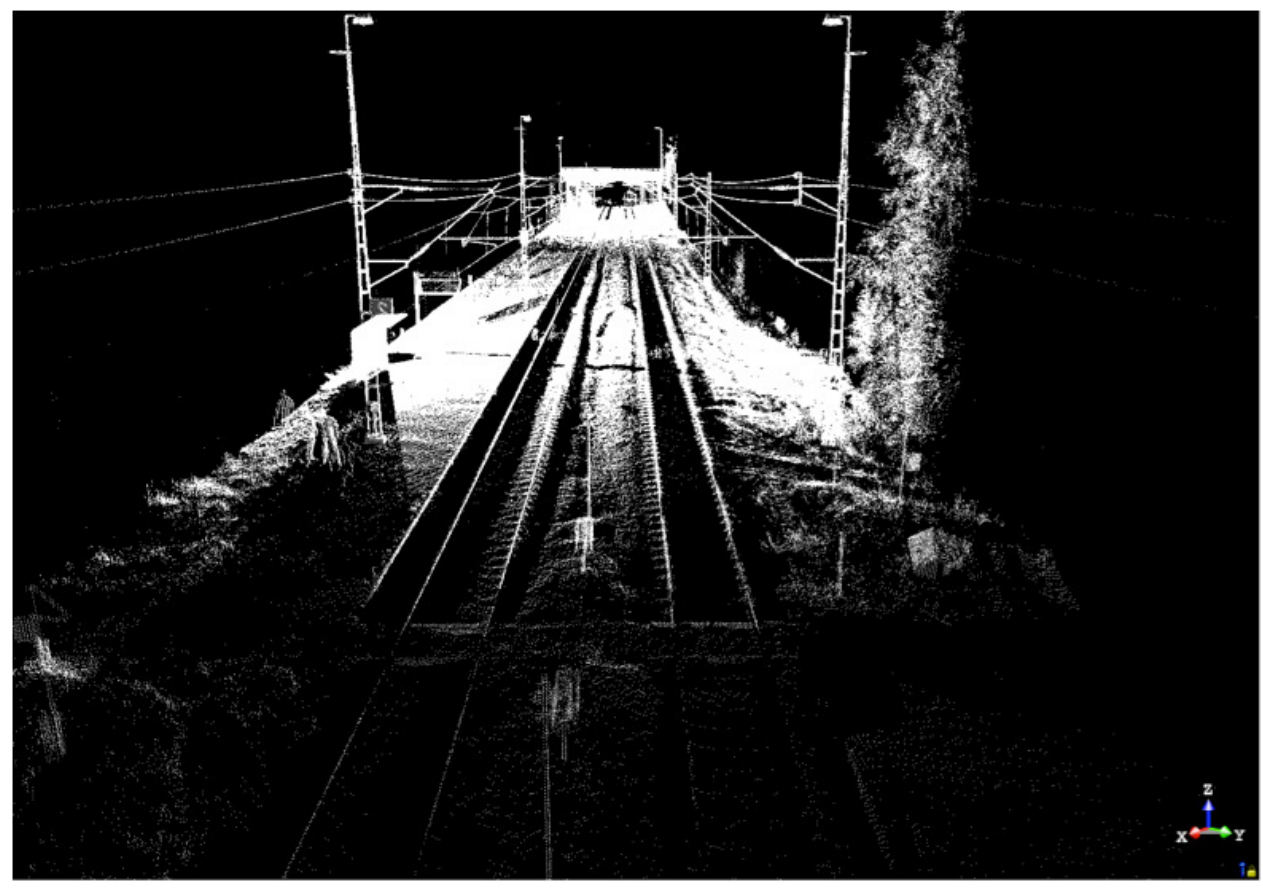

Figure 7. The reference point cloud measured by Riegl VZ-1000 laser scanning system. 


\section{CONCLUSIONS}

Based on these experiments and results, the applicability of the UAV measurement principle is good to the measurement of 3-D digital terrain model of rather small areas. In the Jorvas railway yard case, ground surface, rails and other existing structures were able to capture in 3-D. There were met some problems due to quite late Fall measurement time, "too bright" sun shining weather together with the movements of shadows, and for too steady asphalt pavement surface, where no clear single points were able to capture by the UAV camera used.

In Finland, there have been reported that the accuracy of measurement achieved recently in some other projects has been about $\pm 3 \ldots \pm 5 \mathrm{~cm}$ ( $\mathrm{z}$ direction), no such a detailed research report has, however, been published. In this project this kind of accuracy was not achieved. The principle of measurement includes a lot of redundancy and the final derivates are calculated trough adjustment using Leas Squares optimization method. Thus, the reliability of the measurement principle is theoretically at high level. Due to the principle to capture multiple images from each ground surface local area, there remains to have good possibilities to observe the same measurement points from each photo. Also, there is a possibility to conduct and attend the map of residual errors of each coordinate point in the calculation method. The observed benefits did not exceed the measurement costs in this project. However, several economic potentials were seen and observed related to UAV measurement for rather small digital terrain model measurements. The cost effectiveness of the UAV measurement in such rather limited areas like 50500 hectare was evaluated to excellent. If the final point density of about 0.5-1.0 points per square meter is needed for the point cloud, the UAV remains to be a very applicable and cost effective measuring method.

In all, the UAV measurement principle was evaluated to very potential surveying method being still, however, at some developing technical level. When using that kind of measurement method, to avoid any possible geoid and other measurement errors, you should in any cases try to connect measurements to the local coordinate measurement systems. During the measurements on that late Fall season time, there was a very bright sunny daytime causing strong moving shadows to the measurement range, and thus producing a lot of difficulties into the photogrammetric measurement process. Steady, bright, but cloudy weather on Mid-Summer time would have been much better for this principle of measurement. During nature growing time there can be a lot of leafs preventing sight from camera to ground surfaces. Thus, leafless time before Summer or after that, would be much better for UAV measurements. The accuracy of the signalled reference points used is very critical to achieve the best possible accuracy of measurements by the UAV method. Thus, the use of robotic total station for these measurements is strongly recommended. Finally, the study of the UAV method offers a good information to the development of the Infra FINBIM specifications, which work is right now active in Finland.

\section{REFERENCES}

Cooper, M. A. R. 1987. Control Surveys in Civil Engineering. London, The City University, Department of Civil Engineering. $381 \mathrm{~s}$.

Heikkilä, R. (1996) The Applicability of an Electro-Optical Coordinate Measuring Technique to the Dimensional Control of Precast Concrete Facade Panel Production. Oulu, Acta Universitatis Ouluensis, Technica C 86.87 p. + Appendixes.

Heikkilä, R. \& Kivimäki, T. \& Mikkonen, M. \& Lasky, T. A. (2010) Stop \& Go Scanning for Highways 3D Calibration Method for a Mobile Laser Scanning System. ISARC'2010, The 27th International Symposium on Automation and Robotics in Construction, 25-27 June 2010, Bratislava, Slovakia, pp. $40-48$.

Sydenham, P. H. (1982) Handbook of Measurement Science. Volume 1. Theoretical Fundamentals. Singapore, John Wiley \& Sons, p. 1-654. 
Sydenham, P. H. (1983) Handbook of Measurement Science. Volume 2. Practical Fundamentals. Singapore, John Wiley \& Sons, p. 655-1413. 